\title{
Research on Optimization of Aircraft Climb Trajectory considering Environmental Impact
}

\author{
Fangzi Liu, ${ }^{1,2}$ Minghua Hu, ${ }^{1}$ Wenying Lv, ${ }^{1}$ and Honghai Zhang $\mathbb{D}^{1}$ \\ ${ }^{1}$ College of Civil Aviation, Nanjing University of Aeronautics and Astronautics, Nanjing 211106, China \\ ${ }^{2}$ Air Traffic Management Bureau of Civil Aviation Administration of China, Beijing 100000, China
}

Correspondence should be addressed to Honghai Zhang; honghaizhang@nuaa.edu.cn

Received 12 October 2020; Revised 12 December 2020; Accepted 8 January 2021; Published 30 January 2021

Academic Editor: Bin Yu

Copyright (c) 2021 Fangzi Liu et al. This is an open access article distributed under the Creative Commons Attribution License, which permits unrestricted use, distribution, and reproduction in any medium, provided the original work is properly cited.

Trajectory-based operation is a new technology that will be developed in the next generation of air traffic management. In order to clarify the optimization space of fuel consumption and emission impact on the environment under the specific operation limitation of air traffic management in the process of aircraft climb, an aircraft climb performance parameter optimization model considering the environmental impact is established. First, the horizontal and vertical climb models are established for the aircraft climb process, and then the optimization objectives are constructed by considering the impact of fuel consumption, exhaust emissions on air temperature, and the convenience of the flight process. Finally, the multiobjective model is solved by genetic algorithm. The B737-800 civil aviation aircraft is selected for simulation experiment to analyze the impact of speed change on the optimization target. The results show that with the change of speed, the fuel consumption and temperature rise are different, and the climb performance parameters of the aircraft are affected by the maximum RTA. By optimizing the flight parameters of the aircraft, it can effectively reduce the impact of flight on the environment and provide theoretical support for the sustainable development of civil aviation.

\section{Introduction}

The global air traffic system is currently undergoing a comprehensive transformation and upgrading stage to cope with the ever-increasing flight demand, complex and huge system architecture, and diversified operating environment. At the same time, it is continued to meet the comprehensive performance expectations, operational efficiency, cost-effectiveness, and environmental impact of various stakeholders for aviation operations [1]. Trajectory-based operation and performance-based air traffic management have become the key words of global air transport system reform [2]. Through the fine management of flight trajectory, it can solve the airspace operation constraints, optimize the allocation of airspace resources, and build a collaborative, efficient, and environmental protection flight operation state.

The climb stage is an important stage in the flight process of an aircraft. Different flight performance parameters are related to the effectiveness of aircraft flight. This paper studies the climbing stage of aircraft, clarifies the influence mechanism of aircraft climbing performance, and provides theoretical support for optimizing aircraft fuel efficiency and improving environmental friendliness.

In terms of departure trajectory optimization, Ho-Huu et al. established a multiobjective model considering fuel consumption and noise factors and designed a solution algorithm to obtain the optimal trajectory $[3,4]$. Visser et al. $[5,6]$ developed a tool for reducing aircraft takeoff noise based on noise model, geographic information system, and dynamic trajectory optimization algorithm and used B737-300 aircraft in Amsterdam Airport Schiphol has been verified, and a multistage/criterion trajectory optimization framework is proposed for urban to city missions, so that the aircraft can reduce noise and pollutant emissions as much as possible. Prats et al. [7] proposed a strategy for designing aircraft noise reduction procedures to reduce noise nuisance felt by people living around the airport. A nonlinear multiobjective optimization model is 
established and numerically solved to obtain the minimum noise disturbance trajectory. Torres et al. [8] comprehensively considered the impact of noise, $\mathrm{NO}_{\mathrm{x}}$ emissions, and $\mathrm{CO}_{2}$ emissions on the environment, established a nonlinear multiobjective optimization, and solved the optimal departure trajectory of the aircraft. Some scholars have studied the green trajectory of aircraft. Tian et al. [9] used RTA (Required Time of Arrival) issued from tactical ATM (Air Traffic Management) operations as a hard constraint and optimized the whole flight phases, minimising the overall environmental impact. Xu et al. [10] discussed the green trajectory optimization, in the context of EDCT (Expect Departure Clearance Time) constraint imposed by pretactical ATM operations.

In terms of airspace operation restrictions, Ramon and Adrian accurately restricted the arrival time of the waypoints and conducted research on CDO (Continuous Descent Operation) under the RTA mode, and considered that the mode was a potential solution to reduce the impact of fuel consumption, pollutant emissions, and noise in the airport area without damaging the airport capacity. Moreover, it was beneficial to allocate RTA before the aircraft began to descend [11]. Higuchi et al. [12] used a three parameter model to simulate the flight operation of aircraft and optimized the aircraft in approach according to RTA constraints, so as to improve the operation efficiency of busy airports. Vilardaga et al. optimized the $4 \mathrm{D}$ trajectory of the aircraft with RTA constraints by making quantitative trade-offs in terms of fuel and time consumption [13]. Alejandro et al. [14, 15] proposed a method that can provide optimal combination of Mach numbers at different waypoints to meet the arrival time constraint required by the aircraft during the flight at a fixed height while considering the fuel consumption of the aircraft. In the next year, an economic algorithm of vertical reference trajectory is proposed, which satisfies the time of arrival constraint. Compared with the flight cost of the reference trajectory, the RTA constraint is satisfied, and the flight cost of the optimized trajectory is reduced. Wan et al. [16] analyzed the green climb trajectory optimization problem under the constraint of a single waypoint.

The above research mainly considers the influence of fuel economy, noise interference, or airspace operation restrictions on aircraft flight trajectory. In order to more fully clarify the time and space characteristics of the aircraft's trajectory parameters during the climb process, this paper adopts the idea of differentiation and combines the full energy model in BADA to model and analyze the climb process of the aircraft and establish the climb process model of the aircraft with the constraint of multiwaypoint. Considering three optimization goals, namely, fuel consumption, global temperature rise caused by exhaust gas, and minimum flight speed change between constrained segments, a genetic algorithm with elite retention strategy is designed to solve this problem, and hoping to be a concept of green development provides theoretical support for air transportation.

\section{Trajectory Optimization in Climbing Stage}

2.1. Problem Description. Enroute climb generally refers to the climb process in which aircraft climb in a certain way from a height of $1500 \mathrm{ft}$ on the airport ground and increases to the specified cruising height and cruising speed [17]. During the flight process, aircraft should satisfy the waypoint cooperative constraint requirement which is issued by the air traffic management system, coordinate the constraint interval of aircraft' Required Time of Arrival (RTA) and Required Height of Arrival (RHA) at relevant position, construct conflict-free flight paths between aircraft, and avoid potential flight conflicts in airspace. Therefore, aircraft should project their flight distance, flight height, and flight time in advance. This section firstly analyzes the aircraft departure vertical climbing process, including the end of climbing and the beginning of cruising flight. Assuming that aircraft climbs at the constant indicated airspeed, the aircraft departure model is established, and the aircraft climb parameters and level flight parameters are calculated. Then, the aircraft level flight parameters are optimized by comprehensively considering the aircraft fuel consumption, the impact of engine exhaust on the environment, and the flight process convenience. Finally, we introduce the multiobjective optimization mathematical model detailed, and the research framework is shown in Figure 1.

2.2. Vertical Profile of Aircraft Climb. Due to the high maneuverability when aircraft is flying below 10,000 feet and the ATC interference, the flight is less predictable. Therefore, this paper only considers the aircraft climbing stage that over 10000 feet and the beginning section of enroute cruise. On account of aircraft flight trajectory is influenced by many factors in actual operation process, the air traffic management system (ATMS) needs to arrange departing aircraft safe intervals to ensure aircraft flight safe and orderly. In this process, the ATMS should effectively control aircraft flight trajectory, and the common method is publishing aircraft waypoint constraints.

Therefore, we can abstract the aircraft departure climbing flight process with multiple waypoint constraints, starting from point A, climbing to the top of climb (TOC), and ending at point $\mathrm{B}$ with the constant indicated airspeed. The whole process has multiple waypoint constraints. As shown in Figure 2(a), $R$ is the aircraft total flight distance, the whole climbing process could be deemed to a combination of multiple flight steps, and each constrained segment can be represented by $C_{i}(i=1,2, \ldots, m)$. The single step range flight process is $R_{i}$, and it consists of climb range $r_{c, i}$ and cruise range $r_{\mathrm{cr}, i} ; t_{i}$ and $h_{i}$, respectively, represent the flight time and flight height when the aircraft reaches the end of the constrained segment. In Figure $2(\mathrm{~b}), t_{i, \min }$ and $t_{i, \max }$ represent the minimum and maximum RTA time constraints, respectively; $h_{i, \min }$ and $h_{i, \max }$ represent the RHA minimum and maximum height constraints, respectively.

The climbing trajectory is divided into $m$ constrained segments by introducing the concept of microelements, and each segment $C_{i}(i=1,2, \ldots, m)$ is divided into $n$ microelements. For example, the $i$-th element in segment $j(j=$ $1,2, \ldots, n)$ can be denoted as $C_{i, j}$. The aircraft flight parameters could be determined according to the flight parameters at the microelement intermediate trajectory point; 


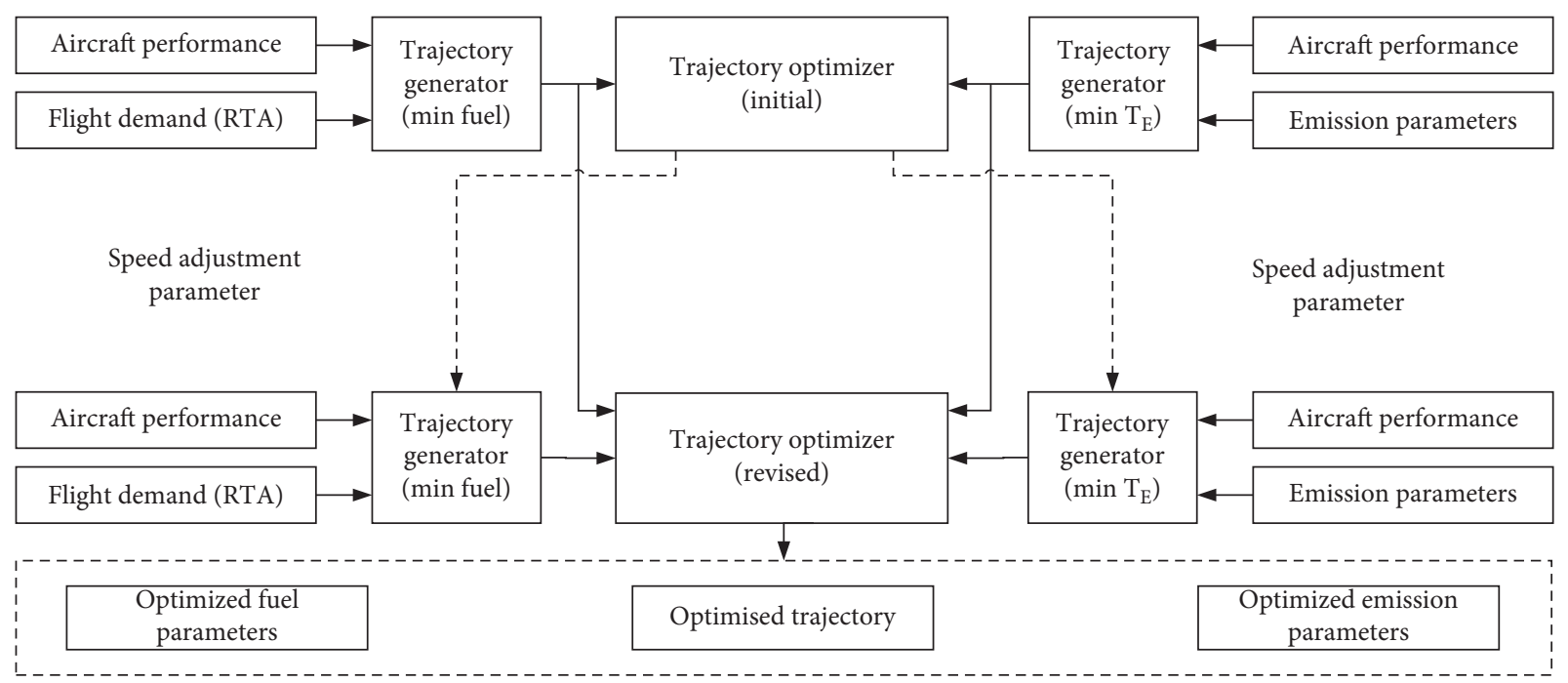

Figure 1: Problem research framework.

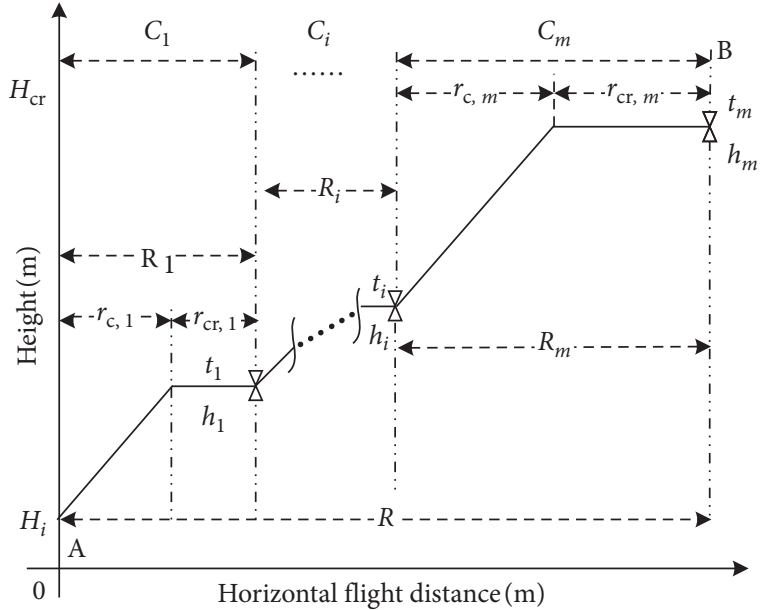

(a)

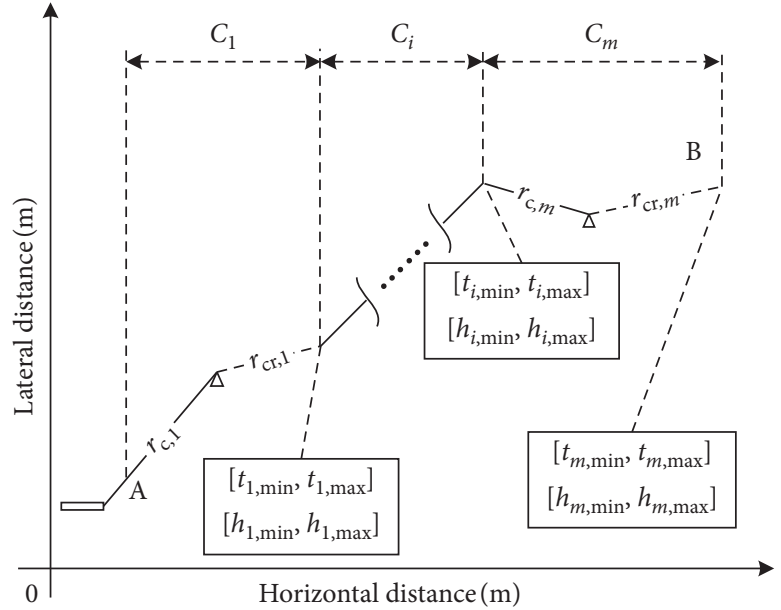

(b)

Figure 2: Aircraft multiple waypoint collaborative constraint departure mode. (a) Vertical trajectory pattern. (b) Horizontal trajectory pattern.

when the aircraft is located at the intermediate point of $C_{i, j}$ microelement, the flight distance from $\mathrm{A}$ is $r_{i, j}$ :

$$
r_{i, j}= \begin{cases}r_{i, j-1}+\Delta r, & r_{c, i}<r_{i, j-1}-R_{i-1}<R_{i}, \\ r_{i, j-1}+\frac{\Delta h \times\left(V_{T, i, j}+V_{W, \mathrm{mps}, i}\right)}{\gamma_{c, i, j}}, & r_{i, j-1}-R_{i-1} \leq r_{c, i},\end{cases}
$$

where $V_{\mathrm{W}, \mathrm{mps}, i}$ is the wind speed in the current segment $(\mathrm{m} / \mathrm{s}) ; \Delta r$ is the flight distance of a microelement; and $\gamma_{c, i, j}$ is the climbing rate $(\mathrm{m} / \mathrm{s})$; details are as follows:

$$
\gamma_{c, i, j}=\frac{\left(T_{i, j}-D_{i, j}\right) \cdot V_{T, i, j}}{m_{A, i, j} \cdot g} f\left\{M_{i, j}\right\} .
$$

The flight height of the aircraft at the middle point of the $C_{i, j}$ is

$$
h_{i, j}= \begin{cases}h_{i-1}, & r_{c, i}<r_{i, j-1}-R_{i-1}<R_{i}, \\ h_{i, j-1}+\Delta h, & r_{i, j-1}-R_{i-1} \leq r_{c, i} .\end{cases}
$$

The flight time for the aircraft to reach the middle point of the $C_{i, j}$ is

$$
t_{i, j}= \begin{cases}t_{i, j-1}+\frac{\Delta r}{\left(V_{T, i, j}+V_{W, \mathrm{mps}, i}\right)}, & r_{c, i}<r_{i, j-1}-R_{i-1}<R_{i}, \\ t_{i, j-1}+\frac{\Delta h}{\gamma_{c, i, j}}, & r_{i, j-1}-R_{i-1} \leq r_{c, i} .\end{cases}
$$


In order to determine the specific leveling and climbing distance within a certain restricted section, assuming the level flight distance within the constraint segment is known, and the climbing distance can be expressed as

$$
r_{\mathrm{c}, i}=R_{i}-r_{\mathrm{cr}, i}
$$

$\Delta r$ and $\Delta h$ that under the collaborative constraint of multiple waypoints are calculated as follows:

$$
\left\{\begin{array}{l}
\Delta r=\min \left\{\Delta r_{0}, \sum_{j} R_{i-1}+r_{c, i}-r_{i, j-1}\right\}, \\
\Delta h=\min \left\{\Delta h_{0}, h_{i-1}-h_{i, \min }\right\} .
\end{array}\right.
$$

To sum up, the aircraft flight trajectory parameters of climbing process can be described by the following formula:

$$
\left\{\begin{array}{l}
R=\left[\begin{array}{llllll}
r_{1,1} & r_{1,2} & \ldots & r_{i, j} & \ldots & r_{m, n}
\end{array}\right] \\
H=\left[\begin{array}{llllll}
h_{1,1} & h_{1,2} & \ldots & h_{i, j} & \ldots & h_{m, n}
\end{array}\right] \\
T=\left[\begin{array}{llllll}
t_{1,1} & t_{1,2} & \ldots & t_{i, j} & \ldots & t_{m, n}
\end{array}\right]
\end{array}\right.
$$

where $\mathrm{R}, \mathrm{H}$, and $\mathrm{T}$ are, respectively, represent aircraft flight distance matrix, height matrix, and time matrix that under the multiwaypoint constraints. Each constraint section of aircraft leveling flight distance matrix $\mathrm{R}_{\mathrm{cr}}$ during departures could be described by the following formula:

$$
R_{c r}=\left[\begin{array}{llllll}
r_{c r, 1} & r_{c r, 2} & \ldots & r_{c r, i} & \ldots & r_{c r, m}
\end{array}\right] .
$$

The multiwaypoint constraints include the RHA constraint and the RTA constraint of each constraint segment. In Figure 2(b), each constraint section RHA constraint is given in the form of height interval; details are as follows:

$$
H_{\text {constrain }}=\left[\begin{array}{llllll}
h_{1, \max } & h_{2, \max } & \ldots & h_{i, \max } & \ldots & h_{m, \max } \\
h_{1, \min } & h_{2, \min } & \ldots & h_{i, \min } & \ldots & h_{m, \min }
\end{array}\right] .
$$

RTA constraint is given in the form of time interval and can be expressed as follows:

$$
T_{\text {constrain }}=\left[\begin{array}{llllll}
t_{1, \max } & t_{2, \max } & \ldots & t_{i, \max } & \ldots & t_{m, \max } \\
t_{1, \min } & t_{2, \min } & \ldots & t_{i, \min } & \ldots & t_{m, \min }
\end{array}\right] .
$$

2.3. Aircraft Climbing Performance Parameters. The full energy model in BADA is used to model the aircraft climbing process. The work performed by the external force on the aircraft is equal to the change in the aircraft mechanical energy. During the climbing process, the force on the aircraft longitudinal axis mainly consists of engine thrust $T_{c}$ and resistance $D$; the calculation formula is as follows:

$$
\left(T_{c}-D\right) V_{T}=m_{A} g \frac{\mathrm{d} h}{\mathrm{~d} t}+m_{A} V_{T}\left(\frac{\mathrm{d} V_{T}}{\mathrm{~d} h}\right)\left(\frac{\mathrm{d} h}{\mathrm{~d} t}\right)
$$

In formula (11), $T_{\mathrm{c}}$ represents the thrust force, $V_{\mathrm{T}}$ represents the true airspeed, and $\mathrm{d} h / \mathrm{d} t$ represents the height change rate.

After the formula transformation, the height change rate $\mathrm{d} h / \mathrm{d} t$ is as follows:

$$
\frac{\mathrm{d} h}{\mathrm{~d} t}=\left[\frac{\left(T_{c}-D\right) V_{T}}{m_{A} g}\right] f\{M\},
$$

where $f\{M\}$ is a function of Mach number $M$, indicating the specific value of the climbing residual thrust and the accelerating residual thrust when climbing at a given speed. In the indicated airspeed climbing process, the specific calculation formula of $f\{M\}$ is given by BADA [18].

For a given climbing height $\Delta H(\mathrm{~m})$, flight time $t_{\mathrm{c}}(\mathrm{s})$ and fuel consumption $F_{\mathrm{c}}(\mathrm{kg})$ during the climbing process can be obtained according to the kinematics and dynamics principles:

$$
\left\{\begin{array}{l}
t_{c}=\frac{\Delta H}{\gamma_{c}} \\
F_{c}=F_{f, c} \cdot t_{c}
\end{array}\right.
$$

where $F_{\mathrm{f}, \mathrm{c}}$ is the climbing fuel flow $(\mathrm{kg} / \mathrm{s})$, and the climbing rate $\gamma_{\mathrm{c}}$ is calculated as follows:

$$
\gamma_{c}=\frac{\left(T_{c}-D\right) \cdot V_{T}}{m_{A} g} f\{M\}
$$

The aircraft maximum climbing thrust $T_{\max \text { climb }}$ can be expressed as

$$
\begin{aligned}
T_{\max \text { climb }}= & C_{T c, 1} \times\left(1-\frac{H_{p, f t}}{C_{T c, 2}}+C_{T c, 3} \times H_{p, f t}^{2}\right) \\
& \times\left[1-C_{T c, 5} \cdot\left(\Delta T-C_{T c, 4}\right)\right],
\end{aligned}
$$

where $C_{T c, 1}, C_{T c, 2}, C_{T c, 3}, C_{T c, 4}$, and $C_{T c, 5}$ are parameters related to the aircraft type; $H_{p, f t}$ is the flight height (unit: $\mathrm{m}$ ). The climbing fuel flow $F_{\mathrm{f}, \mathrm{c}}(\mathrm{kg} / \mathrm{s})$ under the maximum thrust is calculated as follows:

$$
F_{f, c}=\eta \times T h r=C_{f, 1} \cdot\left(1+\frac{V_{T}}{C_{f, 2}}\right) \cdot T_{\max \text { climb }},
$$

where $C_{f, 1}$ and $C_{f, 2}$ are parameters related to the aircraft type.

2.4. Aircraft Leveling Flight Parameters. Aircraft cruise flight could be regarded as a steady leveling flight process without considering aircraft turning. At this moment, aircraft can be regarded as a mass point, the aircraft gravity on the vertical axis is equal to the lift force, and the engine thrust on the vertical axis is equal to the resistance of the aircraft. According to the kinetic equation,

$$
\left\{\begin{array}{l}
m_{A} g=\frac{1}{2} \rho_{H} V_{T}^{2} S C_{L}, \\
T_{c r}=D=\frac{1}{2} \rho_{H} V_{T}^{2} S C_{D},
\end{array}\right.
$$

where $m_{A}$ is the aircraft mass (unit: kg); gravity accelerationg $=9.8 \mathrm{~m} / \mathrm{s}^{2} ; V_{T}$ is the true airspeed (unit: $\mathrm{m} / \mathrm{s}$ ); Sis the wing area (unit: $\mathrm{m}^{2}$ ); $C_{L}$ is the lift coefficient; $T_{\mathrm{cr}}$ is the 
cruise flight engine thrust (unit: $\mathrm{N}$ ); $D$ is the resistance (unit: $\mathrm{N}) ; C_{D}$ is the resistance coefficient; and $C_{D}$ is a function of $C_{L}$ which satisfies the following relation:

$$
C_{D}=C_{D 0, C R}+C_{D 2, C R} \times C_{L}^{2},
$$

where both $C_{D 0, C R}$ and $C_{D 2, C R}$ are the parameters related to the aircraft type, which can be deduced as follows:

$$
T_{c r}=\frac{C_{D 0, C R}}{2} \rho_{H} V_{T}^{2} S+C_{D 2, C R} \times \frac{2 m_{A}^{2} g^{2}}{\rho_{H} V_{T}^{2} S} .
$$

Assuming the aircraft is flying at indicated airspeed $V_{\mathrm{I}}(\mathrm{kt}), V_{\mathrm{T}}$ can be calculated from $V_{\mathrm{I}}$ :

$$
\left\{\begin{array}{l}
M=\sqrt{\frac{2}{K-1}\left\{\left\{\left[\left(1+\frac{K-1}{2}\left(\frac{V_{I}}{a_{0}}\right)^{2}\right)^{(K / K-1)}-1\right] / \delta+1\right\}^{(K-1 / K)}-1\right\}} \\
V_{T}=M \cdot a_{H}
\end{array}\right.
$$

where $\delta=P_{H} / P_{0}$ is pressure ratio; speed of sound is $a_{0}=340.294(\mathrm{~m} / \mathrm{s})$.

In the course of aircraft leveling flight, for a given flight distance $\Delta R(\mathrm{~m})$, cruise flight time $t_{c r}(\mathrm{~s})$ and fuel consumption $F_{c r}(\mathrm{~kg})$ can be calculated according to the kinematic principle, and the specific calculation is as follows:

$$
\left\{\begin{array}{l}
t_{c r}=\frac{\Delta R}{V_{T}+V_{W}}, \\
F_{c r}=F_{f, c r} \cdot t_{c r}
\end{array}\right.
$$

where $V_{W}$ is the effective wind speed (unitm/s) and $F_{f, c r}$ is the cruising fuel flow (unitkg/s):

$$
F_{\mathrm{f}, \mathrm{cr}}=C_{\mathrm{f}, 1} \cdot\left(1+\frac{V_{\mathrm{T}, \mathrm{kt}}}{C_{\mathrm{f}, 2}}\right) \cdot T_{\mathrm{cr}},
$$

where $V_{T, k t}$ is the true airspeed (unit: it) and $C_{f, 1}$ and $C_{f, 2}$ are the parameters related to the aircraft type.

2.5. The Impact of Aircraft Flight on Climate Change. Since different gases have distinguishing radiation properties and the greenhouse effect after emissions also different, how to assess the impact of engine emissions on climate change is particularly important. According to references $[19,20]$, this paper adopts APGTP to evaluate the impact of engine emissions on climate change which is based on Global Temperature Change Potential (GTP). The calculation formula of APGTP represented by $T_{P, x}\left({ }^{\circ} \mathrm{C} / \mathrm{kg}\right)$ is as follows:

$$
T_{P, x}=\frac{A_{x}\left(e^{-T_{h} / \alpha_{x}}-e^{-T_{h} / \tau}\right)}{C\left(\tau^{-1}-\alpha_{x}^{-1}\right)},
$$

where $x$ is the emission gas category, including $\mathrm{CO}_{2}$ and $\mathrm{NO}_{\mathrm{x}} ; A_{x}$ is the radiation forcing caused by the emission of $1 \mathrm{~kg}$ of greenhouse gases (unitW $\cdot \mathrm{m}^{-2} \cdot \mathrm{kg}^{-1}$ ); $T_{h}$ is the time scale on which the emission of gases affects the ambient temperature (unit: year); $\alpha_{x}$ is gas life cycle (unit: year); $\tau$ is the time scale of climate change response (unit: year); and Cis the climate system environmental heat capacity (unit year $\left.\cdot \mathrm{W} \cdot \mathrm{m}^{-2} \cdot{ }^{\circ} \mathrm{C}^{-1}\right)$. The impact of gas emissions on the environment can be expressed as global total temperature rise $T_{E}$, and the calculation formula is as follows:

$$
T_{E}=\sum_{x} E_{x} \cdot T_{P, x}
$$

where $E_{x}$ is the emission of gas $x$. According to the reference (24), selecting 20-year greenhouse gas emissions to explore the impact of climate change and obtain the APGTP of two greenhouse gas emissions on a 20-year time scale, $T_{P, \mathrm{CO}_{2}}=$ $8.3 \times 10^{-16}\left({ }^{\circ} \mathrm{C} / \mathrm{kg}\right)$ and $T_{P, \mathrm{NO}_{x}}=-510 \times 10^{-16}\left({ }^{\circ} \mathrm{C} / \mathrm{kg}\right)$. Then, on the basis of ICAO engine exhaust emission database [21], achieving different reference emission indexes and the specific calculation method of engine emissions is as follows:

$$
\left\{\begin{array}{l}
E_{\mathrm{CO}_{2}}=F_{\mathrm{cff}} \cdot t \cdot E_{I, \mathrm{CO}_{2}} \\
E_{\mathrm{NO}_{\mathrm{x}}}=F_{\mathrm{cff}} \cdot t \cdot e^{H_{S}} \cdot\left(\frac{\delta_{a}^{1.02}}{\theta_{a}^{3.3}}\right)^{0.5} \cdot E_{I, \mathrm{NO}_{x}},
\end{array}\right.
$$

where $E_{\mathrm{CO}_{2}}$ and $E_{\mathrm{NO}_{\mathrm{x}}}$ are the emissions of $\mathrm{CO}_{2}$ and $\mathrm{NO}_{\mathrm{x}}$, respectively (unitg); $F_{\text {cff }}$ is the aircraft single-engine-modified fuel flow (unitkg/s); $t$ is the flight time (units); and $E_{\mathrm{I}, \mathrm{CO}_{2}}$ and $E_{\mathrm{NO}}$ are the engine reference emission indexes of $\mathrm{CO}_{2}$ and $\mathrm{NO}_{\mathrm{x}}$, respectively (unitg/kg). $E_{\mathrm{I}, \mathrm{NO}_{\mathrm{x}}}$ is obtained by linear interpolation of the emission index and modified fuel flow provided by the engine manufacturer in a logarithmic coordinate system. $H_{S}$ is atmospheric humidity ratio; $\delta_{\mathrm{a}}$ is the ratio of the engine inlet pressure to the standard atmospheric pressure; $\theta_{a}$ is the ratio of the engine inlet temperature to the standard atmospheric temperature; $\mathrm{e}$ is the natural base; $F_{\text {cff }}$ is modified fuel flow which is using Boeing Method 2 (BM2) to modify the actual fuel flow [22].

\section{Multipoint Collaborative Optimization Model and Optimization}

3.1. Multiobjective Function Model. In order to satisfy the specific air traffic management operation constraints, three optimization objectives should be taken into comprehensive 
consideration:(1) reducing aircraft fuel consumption as much as possible; (2) the total global temperature rise is as small as possible; (3) intersegment speed changes as little as possible.

ATM systems issue RTA and RHA constraint instructions. The essence of RTA and RHA constraint instructions is to require the aircraft to pass through the height interval after flying a certain distance within a certain time interval. In the departure process, assuming the flight speed in the same constraint segment remains unchanged and the flight speed between segments is variable. When the aircraft flies according to a given RTA interval, for each constraint section, the flight speed should meet the corresponding indicated airspeed change range. The multiobjective optimization model is specifically expressed as follows:

$$
\begin{aligned}
\min & \left\{\lambda_{1} F+\lambda_{2} T_{E}+\lambda_{3} \sum_{i=2}^{m} \Delta V_{I, i}\right\}, \\
& \left\{\begin{array}{l}
h_{i, \min } \leq h_{i, n} \leq h_{i, \max }, \\
t_{i, \min } \leq t_{i, n} \leq t_{i, \max } \\
V_{I, \min } \leq V_{I, i} \leq V_{I, \max },
\end{array}\right.
\end{aligned}
$$

where $\lambda_{1}, \lambda_{2}$, and $\lambda_{3}$ represent the parameters of the impact of the three objectives on the optimization results.

The objectives of flight parameter optimization under multipoint constraint include fuel consumption, total temperature rise, and airspeed variation between constrained segments. When the flight meets the RHA and RTA constraints, according to the aircraft flight status parameters, for aircraft flighting along a multiwaypoint constrained departure trajectory, the total temperature rise data caused by fuel consumption and engine exhaust emissions during departure can be obtained.

\subsubsection{Fuel Consumption}

$$
F=\sum_{i=1}^{m} \sum_{j=1}^{n} F_{f, i, j} \cdot t_{i, j}
$$

3.1.2. Temperature Rise. The total temperature rise caused by aircraft engine emissions $T_{\mathrm{E}}$ is shown as follows:

$$
T_{E}=\sum_{j=1}^{n} E_{x, j} \cdot \sum_{x} T_{P, x}
$$

3.1.3. Airspeed Variation between Constrained Segments. Adopting indicated airspeed flight within the constrained segments, and the airspeed variation between the two adjacent constraint sections is as follows:

$$
\Delta V_{I, i}= \begin{cases}0, & i=1, \\ \left|V_{I, i}-V_{I, i-1}\right|, & i \neq 1,\end{cases}
$$

where $V_{I, i}$ and $V_{I, i-1}$ are the flight speed in constraint section $i$ and section $i-1$, respectively.
3.2. Fitness Function. Due to the optimization process needs to consider three optimization objectives. Except for fuel consumption and total temperature rise, the indicated airspeed variations between different constrained segments are considered, and the indicated airspeed variations greatly affect the flight convenience.

It is necessary to set up a reasonable fitness function to transform the multiobjective problem into a single-objective problem. The fitness function $f$ can be specifically expressed as follows:

$$
f=\left(w_{1} \sum_{i=1}^{m} \frac{F_{i}}{F_{r}}+w_{2} \sum_{i=1}^{m} \frac{T_{i}}{T_{r}}+w_{3} \sum_{i=2}^{m} \frac{\Delta V_{I, i}}{(m-1)\left(V_{I, \max }-V_{I, \min }\right)}\right)^{-1},
$$

where $w_{1}, w_{2}$, and $w_{3}$ are the weights of the three variables, $w_{1}+w_{2}+w_{3}=1 ; F_{i}$ is segment fuel consumption; $T_{i}$ is total temperature rise; $F_{r}$ is reference fuel consumption; and $T_{r}$ is reference total temperature rise. The specific setting method and necessity are given below.

3.3. Optimize Process. The GA optimization model under multiwaypoint constraint is shown in Figure 3.

The model adopts multiobjective GA to optimize decision variables set $\left\{V_{I, i}\right\}$ within each constraint section and obtains the parameters that meet the optimization goal when indicated airspeed change little. Applying the roulette method to select parents, selective probability is 0.5 ; the single-point crossover and mutation were performed on the parents after the selection operation, and the crossover probability is 0.9 and the mutation probability is 0.1 . The individual with the highest fitness value in the current generation is passed to the next generation with a transmission probability of 1 , ensuring that the optimization algorithm converges quickly, and the parent will not deteriorate after cross mutation.

\section{Simulation and Evaluation}

4.1. Simulation Parameter Setting. In this simulation, we choose to optimize B737-800 civil aircraft climb trajectory, and we apply the above optimization model to achieve the optimization goal. Assuming the aircraft is flying under standard atmospheric conditions, temperature deviation is $\Delta T=0^{\circ} \mathrm{C}$, calm wind and flight distances are $R=150 \mathrm{~km}$, initial mass is $65000 \mathrm{~kg}$, initial climb altitude is $H_{i}=10000 \mathrm{ft}$, TOC is $27000 \mathrm{ft}$, and the flight distances and climb altitude within a microsegment are $\Delta r_{0}=1000 \mathrm{~m}$ and $\Delta h_{0}=1000 \mathrm{ft}$, respectively. Indicated airspeed variation range is 200-310 kt. The specific settings are shown in Table 1.

Each constraint segment range is as follows.

$$
\left[\begin{array}{ll}
R_{1} & R_{2}
\end{array}\right]=\left[\begin{array}{ll}
50000 \mathrm{~m} & 100000 \mathrm{~m}
\end{array}\right]
$$

Without considering the RTA constraint, for the determined flight altitude and flight distance, the optimization target is mainly affected by the flight speed. By traversing and calculating the flight parameters at different indicated airspeed, the general rule of how indicated airspeed affects 


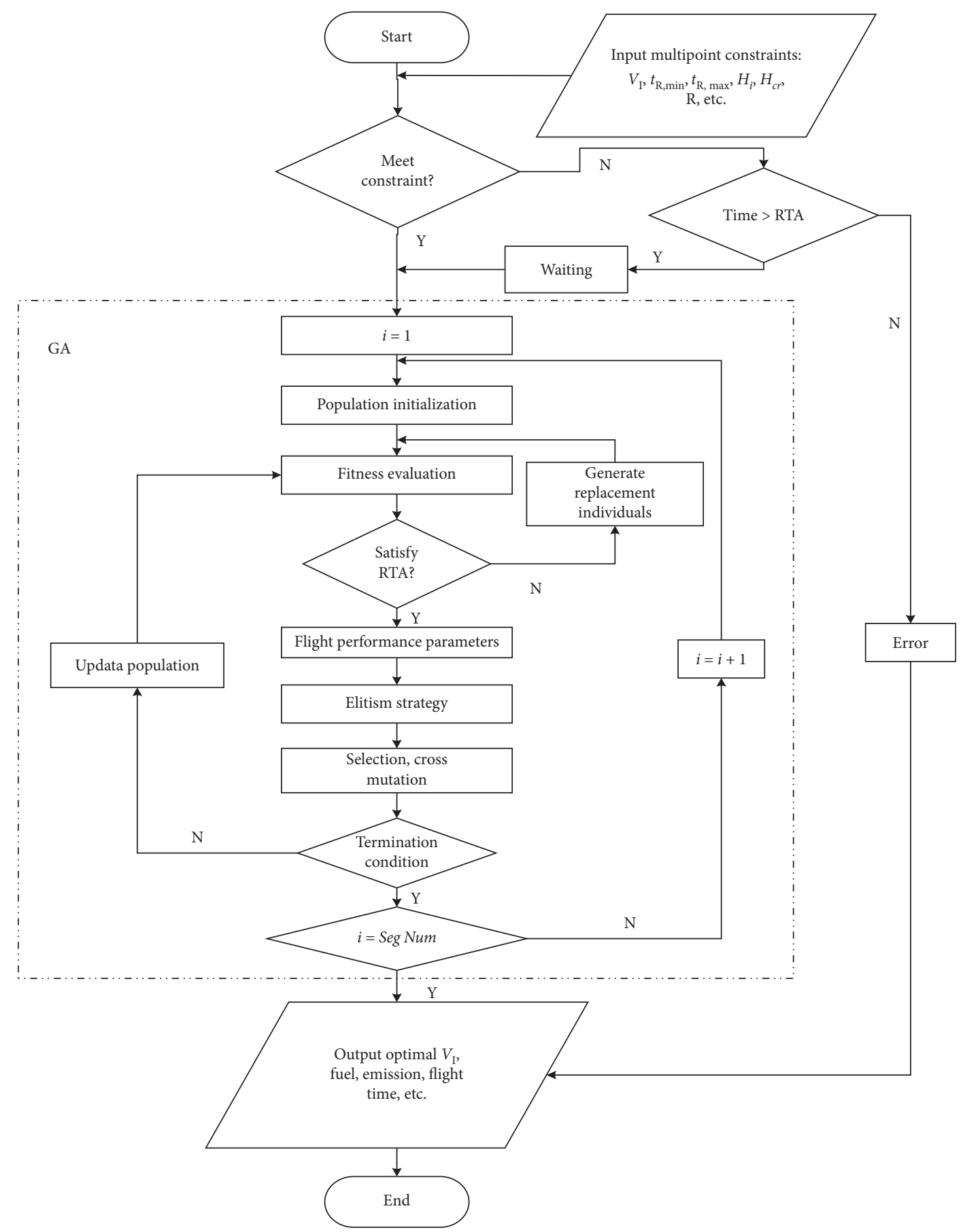

FIGURE 3: Multiple waypoint genetic algorithm optimization model.

TABLE 1: Simulation basic parameters.

\begin{tabular}{lccccccccc}
\hline Parameters & $\Delta T\left({ }^{\circ} \mathrm{C}\right)$ & Wind speed $(\mathrm{kt})$ & $R(\mathrm{~km})$ & Mass $(\mathrm{kg})$ & $H_{i}(\mathrm{ft})$ & TOC $(\mathrm{ft})$ & $\Delta r_{0}(\mathrm{M})$ & $\Delta h_{0}(\mathrm{ft})$ & $\mathrm{Speed}(\mathrm{kt})$ \\
\hline Data & 0 & 0 & 150 & 65000 & 10000 & 27000 & 1000 & 1000 & $200-310$ \\
\hline
\end{tabular}

flight parameters can be obtained. Setting the end altitude of each constraint segment is as follows:

$$
\left[\begin{array}{ll}
h_{1} & h_{2}
\end{array}\right]=\left[\begin{array}{ll}
18000 \mathrm{ft} & 27000 \mathrm{ft}
\end{array}\right] \text {. }
$$

Setting the $V_{I, i}$ change step is $5 \mathrm{kt}$, and the impact of indicated airspeed on the optimization goal is shown in Figure 4. With the flight speed increase, the total temperature rise, $\mathrm{NO}_{\mathrm{x}}$ emission, and $\mathrm{CO}_{2}$ emission corresponding to the aircraft fuel consumption and exhaust gas emission generally show an increase firstly and a decreasing trend later, but the turning points corresponding to each part are different. The speed corresponding to the minimum fuel consumption is around $260 \mathrm{kt}$, and the minimum total temperature rise corresponding to the exhaust emission is 

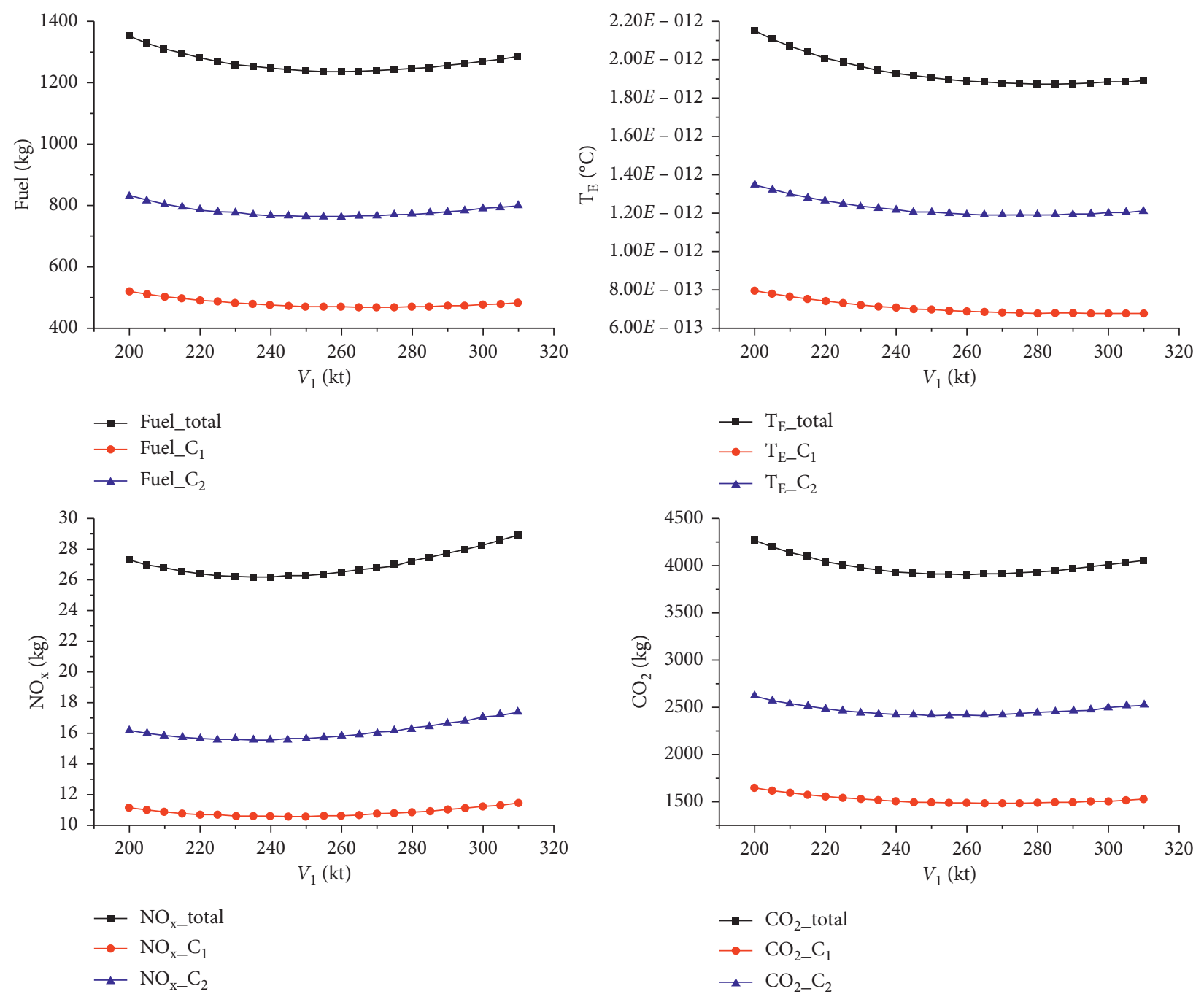

FIGURE 4: The impact of speed changes on optimization goals and emissions.

around $270 \mathrm{kt}$. Therefore, we can figure out a contrary relationship between the aircraft fuel consumption and the corresponding engine exhaust emission, so the optimization method can be used for compromise optimization.

Due to fuel consumption is directly proportional to $\mathrm{CO}_{2}$ emissions, the corresponding minimum values of $F$ and $E_{\mathrm{CO}_{2}}$ in Figure 4 are both $260 \mathrm{kt}$. However, the other three parameters and minimum values correspond to different $V_{I, i}$. For APGTP with a time scale of 20 years, there is an effect of increasing temperature, but the total effect on temperature changes is reduced. This makes the indicated speed corresponding to the minimum value different from the indicated speed corresponding to the minimum value of F.

Table 2 shows the parameter changes corresponding to the minimum fuel consumption and the minimum total temperature rise. According to Table 2, we can sum up the flight indicated airspeed corresponding to the total Fminimum condition and the total Fminimum condition is different. This deviation makes sense for the tradeoff between fuel consumption and overall global warming. Compared with the optimal total $T_{E}$, the total $F$ fuel consumption is reduced by $0.71 \%$, and the total temperature rise increase is increased by $0.69 \%$.

In order to analyze the climb trajectory change rules corresponding to different indicated airspeed, set the indicated airspeed change interval is [200,300]kt and step size is $20 \mathrm{kt}$, and draw the aircraft's climb trajectory as shown in Figure 5. In the climbing process, the higher the speed is, the gentler the climbing process is, and the optimal climbing speed at low height is higher than that at high height.

4.2. Optimization Result Analysis. Different weight factors correspond to different optimization results, and we set different weight combinations for experiments and analyze the results under different values. Considering the randomness of algorithm calculation, we run program 5 times and record the optimizing results under different weight factor combination. Meanwhile, we draw growth process of 
TABLE 2: Flight parameter variation with minimum fuel consumption and total temperature rise.

\begin{tabular}{lccccc}
\hline Condition & $V_{\mathrm{I}}(\mathrm{kt})$ & $F(\mathrm{~kg})$ & $T_{\mathrm{E}}\left(\times 10^{-12 \circ} \mathrm{C}\right)$ & $E_{\mathrm{NO}_{x}}(\mathrm{~kg})$ & 26.511 \\
\hline Total $F$ minimum & 260 & 1238.554 & 1.8912 & $E_{\mathrm{CO}_{2}}(\mathrm{~kg})$ \\
Total $T_{\mathrm{E}}$ minimum & 280 & 1247.401 & 1.8781 & 27.224 & 3907.638 \\
\hline
\end{tabular}

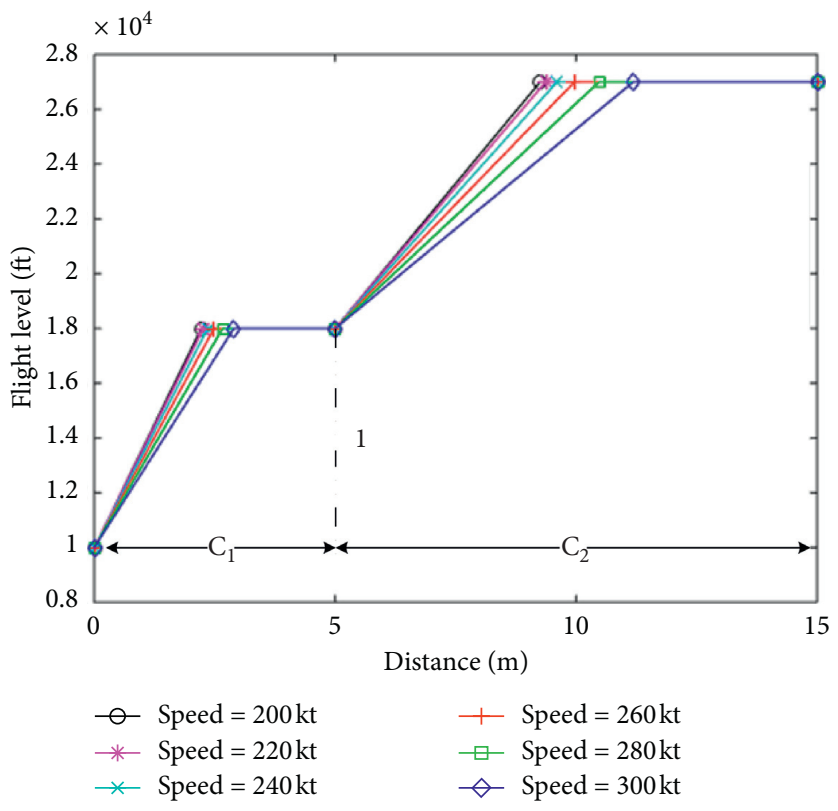

FiguRE 5: Flight trajectories corresponding to different flight speeds.

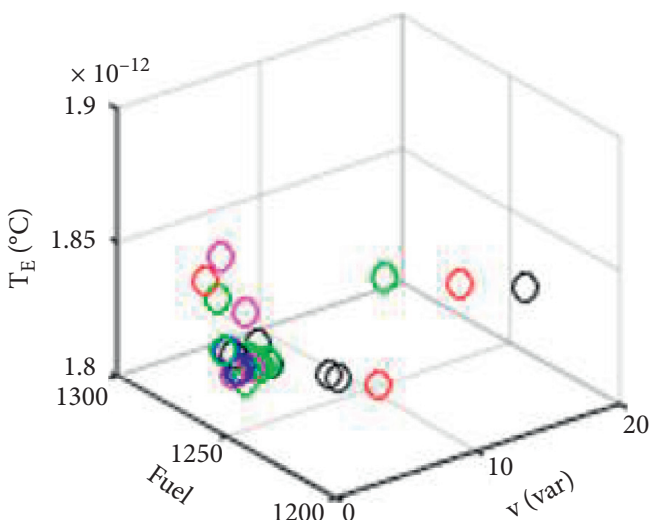

(a)

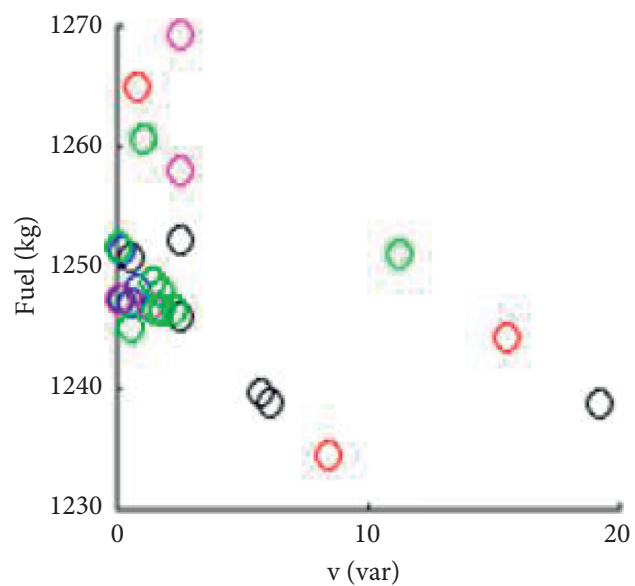

(b)

Figure 6: Continued. 


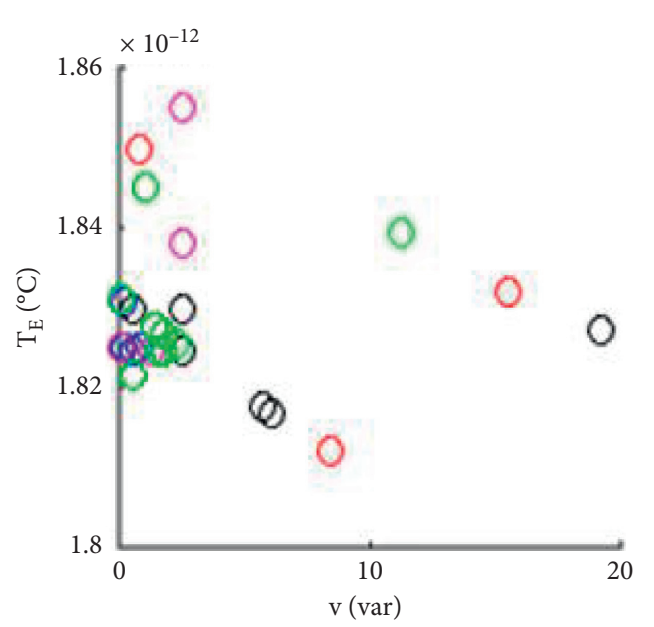

(c)

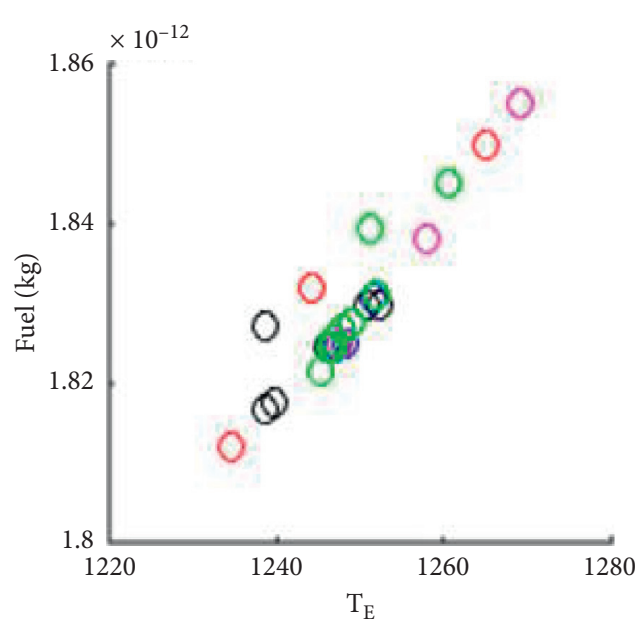

(d)

FIgURE 6: Three optimization objectives and analysis diagram.

$w_{3}$ from 0 to 1 , including 11 kinds of situation and 5 different results, and the total point is 55. In Figure 6, we draw the three objective function optimization results, the three-dimensional figure, and any two optimization objectives scatter. Moreover, we average the 5 results and record them in Table 3 and analyze the 11 kinds of different weight combinations and optimization results, as shown in Figure 7.

Figure 6(a) shows the results of the three optimization objectives with change of $w_{3}$. Figure 6(b) shows the fuel consumption and the airspeed variation ( $\mathrm{v}(\mathrm{var})$ ) with change of $w_{3}$. Figure $6(\mathrm{c})$ shows the total temperature rise and the airspeed variation with change of $w_{3}$. Figure 6(d) shows the total temperature rise and the fuel consumption with change of $w_{3}$. The main part of the optimization result is close to the speed unchanged. Furthermore, the overall trend of fuel consumption and total temperature rise is roughly linear.

As shown in Figure 7, with the increase of $w_{3}$, the airspeed variation gradually approaches 0 , and the optimization fitness gradually increases. When $w_{3}=1$, the fitness increases rapidly. Both fuel consumption and total temperature rise are decreased first and then fluctuant increased. By comprehensively considering the optimization results of airspeed variation, fuel consumption, and total temperature rise as well as the optimization fitness, we can estimate that when $w_{3}=0.1$, the optimum fitness and optimum solution have good convergence, the airspeed variation is moderate, and both fuel consumption and total temperature rise are close to the optimal value.

In order to explore the different combination influence of $w_{1}$ and $w_{2}$ on the optimization results when $w_{3}=0.1$, we test and analyze the optimization results under different $w_{1}$ and $w_{2}$ values, set the $w_{1}$ step size is 0.1 , run the program 5 times, and record each optimization results when $w_{1}$ changes. Then, we record the average of 5 results in Table 4 and analyze 10 kinds of different weight combinations and optimization results, as shown in Figure 8.

As shown in Figure 8, when $w_{3}=0.1$, with the $w_{1}$ increase, fitness shows a decreasing trend while airspeed variation shows an increasing trend; fuel consumption and total temperature rise are basically unchanged. When $w_{1}$ around 0.5 , both fuel consumption and total temperature rise reach the lowest point, and with the $w_{1}$ increase, total temperature rise shows a growth trend. Therefore, selecting $w_{1}=0.5$ achieves the optimal optimization goal when $w_{3}=0.1$. Similarly, the influence of $w_{2}$ change on optimization results is analyzed when $w_{3}=0.1$, and the optimal optimization goal is achieved when $w_{3}=0.1$.

According to the above analysis, the three optimization objective weights are set as $w_{3}=0.1, w_{1}=0.5$, and $w_{2}=0.4$, which can not only ensure flight convenience but also realize and optimize fuel consumption and total temperature rise compromise optimization.

4.3. Optimize Parameters and Trajectory Analysis. According to the analysis in Section 4.2, the three optimization objective weights are set as $w_{3}=0.1, w_{1}=0.5$, and $w_{2}=0.4$, which can achieve the best optimized result. Then, we set up a 100-generation iterative process to analyze the parameters and optimization trajectory in the optimization process. As shown in Figures 9 and 10, the calculation results basically reached the convergence in the 25th generation, and the optimization performance was good.

According to the calculation parameters of the optimization process, the parameters converge to the optimal value near the 25th generation, with fitness value of 1.1151, speed difference of $2.9 \mathrm{kt}$, fuel consumption of $1245.4382 \mathrm{~kg}$, global warming of $1.82 \mathrm{E}-12{ }^{\circ} \mathrm{C}, \mathrm{CO}_{2}$ emission of $3879.5401 \mathrm{~kg}$, and $\mathrm{NO}_{\mathrm{x}}$ emission of $27.3727 \mathrm{~kg}$.

4.4. The Influence of RTA Interval on Optimization Results. In order to explore the impact of time constraints on the optimization results, the minimum and maximum values of RTA time interval were changed to ensure that the flight speed under the RTA time constraints met the constraint conditions, and the optimization results were tested and analyzed. Taking the second constraint segment as an example, setting the RTA time interval constraint is as follows: 
TABLE 3: Different weight combinations and optimization results.

\begin{tabular}{|c|c|c|c|c|c|c|c|c|}
\hline \multirow{2}{*}{$w_{1}$} & \multirow{2}{*}{$w_{2}$} & \multirow{2}{*}{$w_{3}$} & \multirow{2}{*}{ Fitness } & \multicolumn{3}{|c|}{ Optimization results } & \multirow{2}{*}{$\mathrm{CO}_{2}(\mathrm{~kg})$} & \multirow{2}{*}{$\mathrm{NO}_{\mathrm{x}}(\mathrm{kg})$} \\
\hline & & & & V_var (kt) & Fuel (kg) & $T_{\mathrm{E}}\left({ }^{\circ} \mathrm{C}\right)$ & & \\
\hline 0.5 & 0.5 & 0 & 1.0111 & 14.5705 & 1245.8700 & $1.83391 E-12$ & 3880.8850 & 27.2005 \\
\hline 0.45 & 0.45 & 0.1 & 1.1166 & 3.7499 & 1243.8161 & $1.82226 E-12$ & 3874.4873 & 27.3247 \\
\hline 0.4 & 0.4 & 0.2 & 1.3247 & 1.7042 & 1249.4549 & $1.82663 E-12$ & 3892.0520 & 27.5250 \\
\hline 0.35 & 0.35 & 0.3 & 1.4347 & 0.8521 & 1247.0179 & $1.82473 E-12$ & 3884.4609 & 27.4387 \\
\hline 0.3 & 0.3 & 0.4 & 1.6726 & 0.5625 & 1253.0039 & $1.83254 E-12$ & 3903.1073 & 27.5890 \\
\hline 0.25 & 0.25 & 0.5 & 1.9890 & 1.4219 & 1251.0381 & $1.83032 E-12$ & 3896.9838 & 27.5329 \\
\hline 0.2 & 0.2 & 0.6 & 2.4717 & 1.4198 & 1246.6654 & $1.82466 E-12$ & 3883.3627 & 27.4223 \\
\hline 0.15 & 0.15 & 0.7 & 3.1743 & 2.7656 & 1250.4562 & $1.82972 E-12$ & 3895.1711 & 27.5152 \\
\hline 0.1 & 0.1 & 0.8 & 4.8133 & 1.2761 & 1263.3120 & $1.84806 E-12$ & 3935.2170 & 27.8072 \\
\hline 0.05 & 0.05 & 0.9 & 9.3217 & 1.0717 & 1254.1837 & $1.83389 E-12$ & 3906.7823 & 27.6224 \\
\hline 0 & 0 & 1 & 201.4523 & 0.5625 & 1245.7658 & $1.82241 E-12$ & 3880.5604 & 27.4208 \\
\hline
\end{tabular}
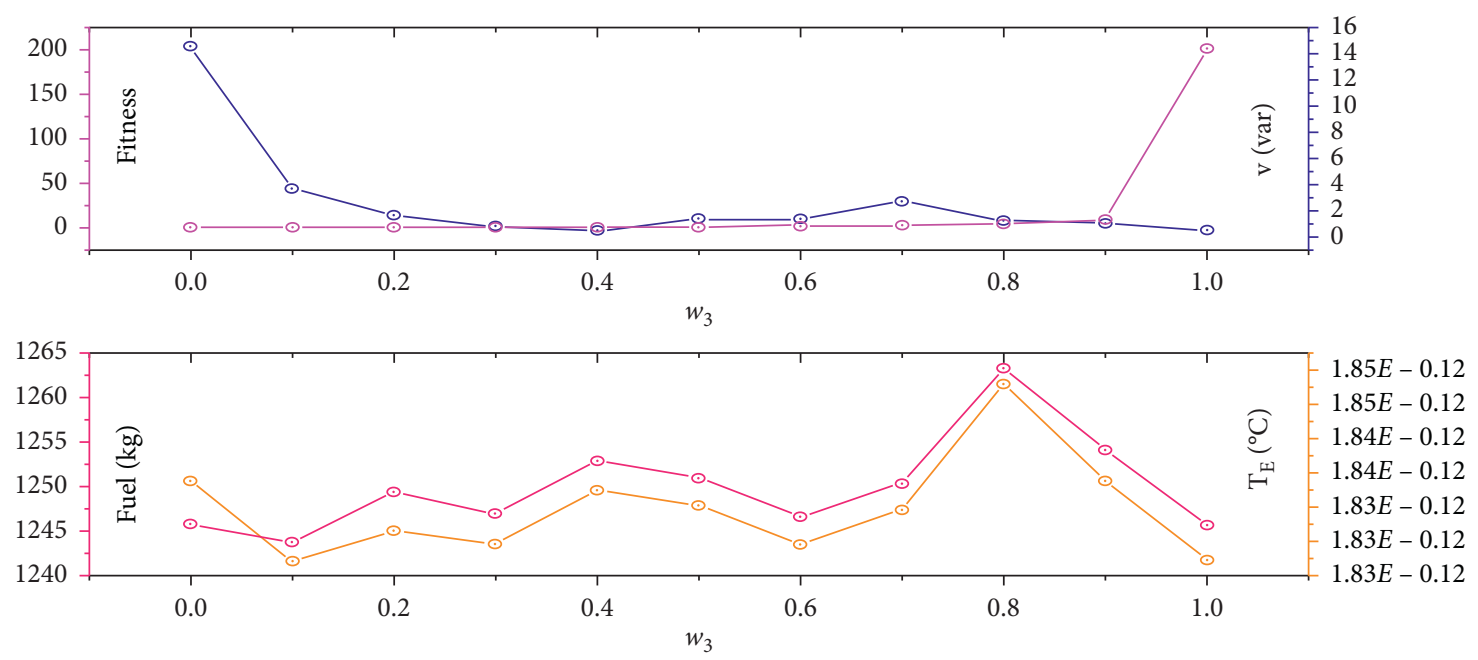

FIgURE 7: Optimization results with change of $w_{3}$ analysis diagram.

TABLE 4: $w_{3}=0.1$ optimized result.

\begin{tabular}{|c|c|c|c|c|c|c|c|c|}
\hline \multirow[b]{2}{*}{$w_{1}$} & \multirow{2}{*}{$w_{2}$} & \multirow{2}{*}{$w_{3}$} & \multirow{2}{*}{ Fitness } & \multicolumn{3}{|c|}{ Optimized result } & \multirow{2}{*}{$\mathrm{CO}_{2}(\mathrm{~kg})$} & \multirow{2}{*}{$\mathrm{NO}_{\mathrm{x}}(\mathrm{kg})$} \\
\hline & & & & V_var (kt) & Fuel (kg) & $T_{\mathrm{E}}\left({ }^{\circ} \mathrm{C}\right)$ & & \\
\hline 0 & 0.9 & 0.1 & 1.1398 & 0.0668 & 1247.5096 & $1.82 E-12$ & 3885.9925 & 27.4615 \\
\hline 0.1 & 0.8 & 0.1 & 1.1335 & 1.2812 & 1246.7496 & $1.82 E-12$ & 3883.6251 & 27.4262 \\
\hline 0.2 & 0.7 & 0.1 & 1.1302 & 0.4219 & 1247.2836 & $1.82 E-12$ & 3885.2884 & 27.4511 \\
\hline 0.3 & 0.6 & 0.1 & 1.1253 & 0.9063 & 1246.9776 & $1.82 E-12$ & 3884.3351 & 27.4370 \\
\hline 0.4 & 0.5 & 0.1 & 1.1208 & 0.9375 & 1246.9701 & $1.82 E-12$ & 3884.3118 & 27.4363 \\
\hline 0.45 & 0.45 & 0.1 & 1.1178 & 1.9359 & 1247.6833 & $1.83 E-12$ & 3886.5336 & 27.4366 \\
\hline 0.5 & 0.4 & 0.1 & 1.1151 & 2.9005 & 1245.4382 & $1.82 E-12$ & 3879.5401 & 27.3727 \\
\hline 0.6 & 0.3 & 0.1 & 1.1101 & 4.0345 & 1248.9455 & $1.83 E-12$ & 3890.4653 & 27.4317 \\
\hline 0.7 & 0.2 & 0.1 & 1.1062 & 4.0313 & 1248.6045 & $1.83 E-12$ & 3889.4030 & 27.4239 \\
\hline 0.8 & 0.1 & 0.1 & 1.1021 & 3.2396 & 1261.9236 & $1.85 E-12$ & 3930.8919 & 27.7258 \\
\hline
\end{tabular}

$$
T_{\text {constrain }}=\left[\begin{array}{ll}
t_{1, \max } & t_{2, \max } \\
t_{1, \min } & t_{2, \min }
\end{array}\right]=\left[\begin{array}{ll}
480 & 820 \\
400 & 760
\end{array}\right] .
$$

4.4.1. The Impact of Minimum RTA Interval on Optimization Results. In formula (33), selecting $t_{2, \max }=820 \mathrm{~s}$, setting the $t_{2, \min }$ variation range is $\left[\begin{array}{ll}760 & 810\end{array}\right] \mathrm{s}$ and step size is $10 \mathrm{~s}$.
Each circulation optimization result is recorded when $t_{2, \min }$ change, as shown in Figure 11. According to Figure $11, t_{2, \text { min }}$ has slight influence on the optimization results of flight parameters under RTA constraint. However, there has been a marked reduction when $t_{2, \min }=800 \mathrm{~s}$. The reason is when the RTA time interval is satisfied, the larger the minimum RTA interval value, the smaller the corresponding 

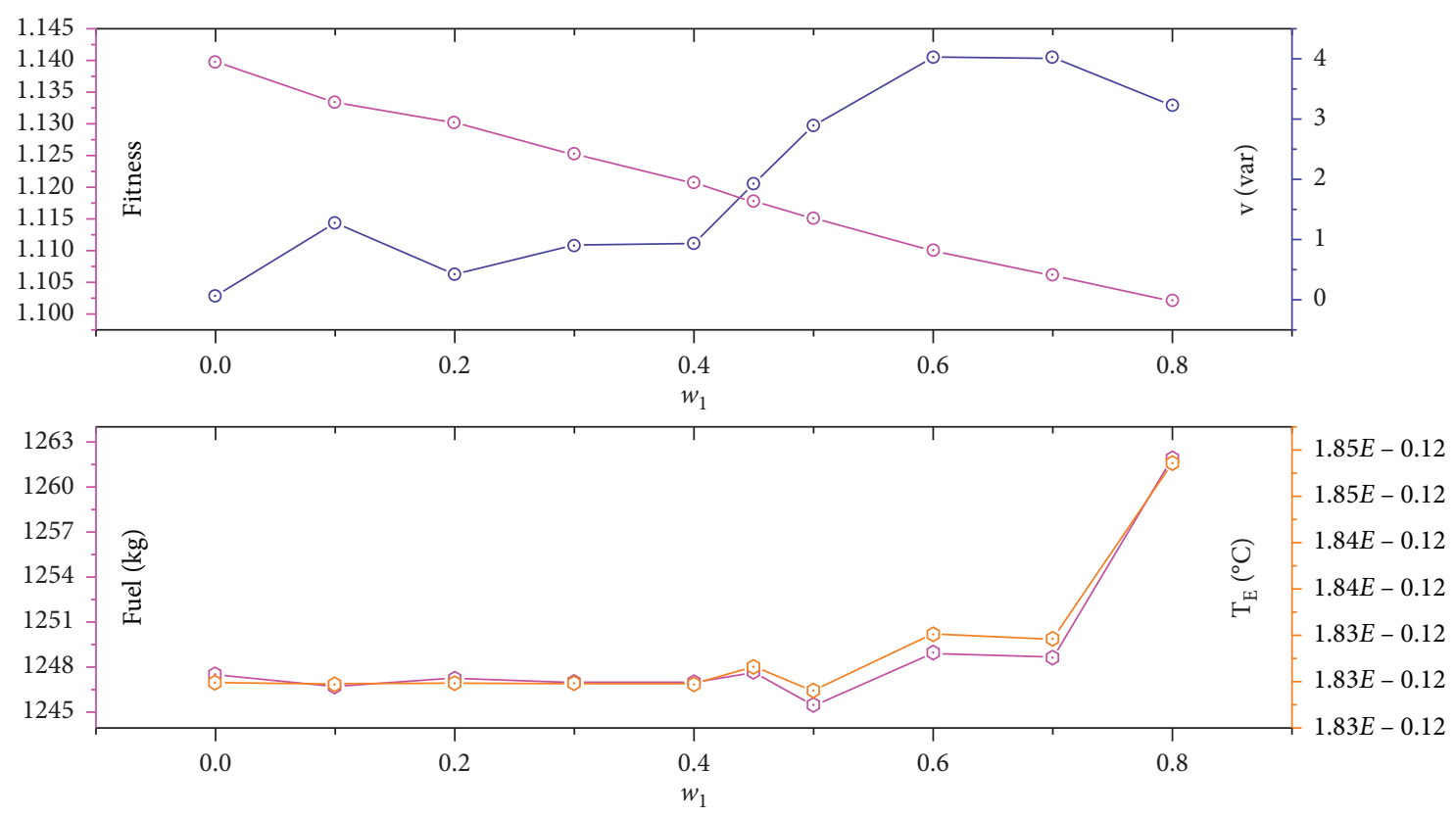

FIGURE 8: The impact of $w_{1}$ change on optimization results when $w_{3}=0.1$.
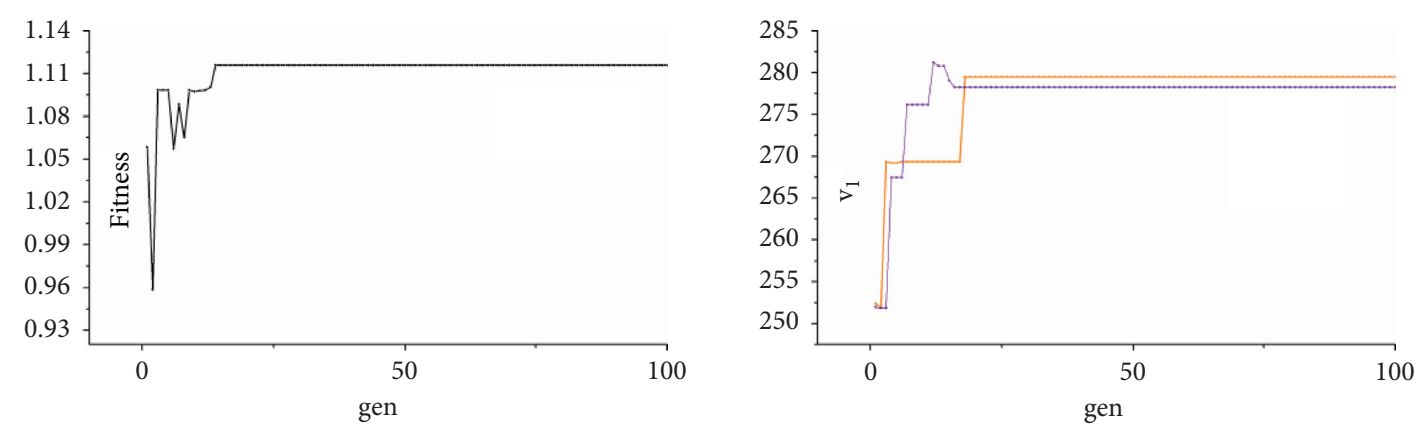

_ Fitness

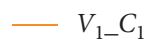

$$
-V_{1-} C_{2}
$$
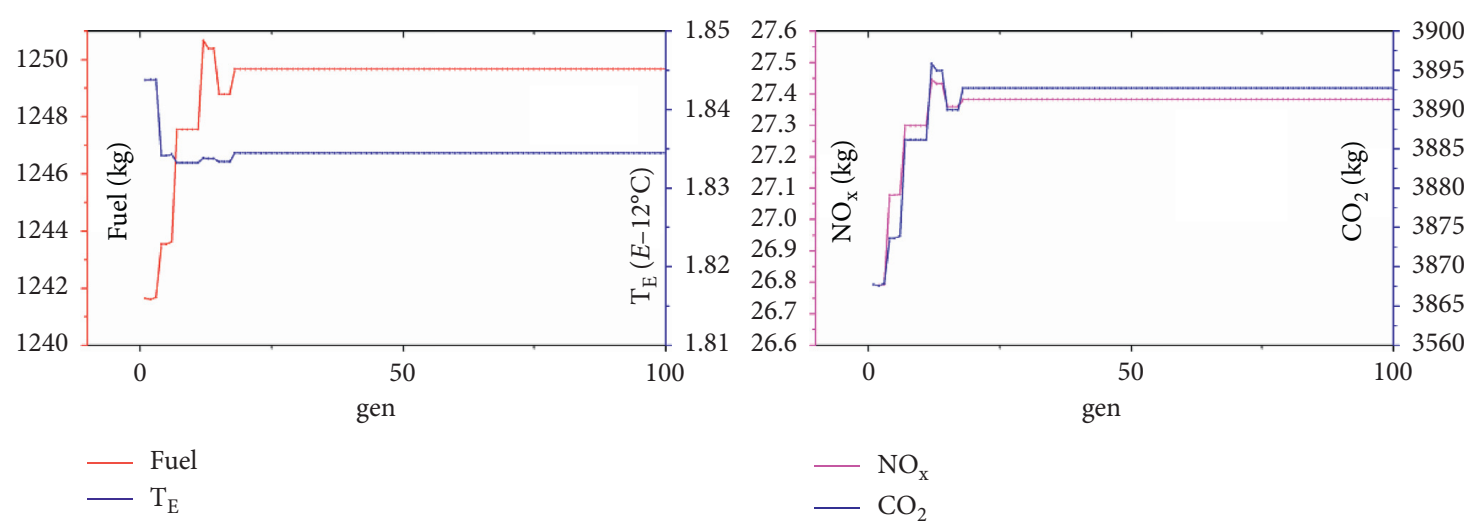

FIGURE 9: Optimize parameters when $w_{1}=0.5, w_{2}=0.4$, and $w_{3}=0.1$.

maximum flight speed. When $t_{2, \min }=870 \mathrm{~s}$, the corresponding maximum flight speed is about $250 \mathrm{kt}$. Meanwhile, the flight speed corresponding to the optimal fuel consumption and warming is around $260 \mathrm{kt}$ to $280 \mathrm{kt}$ (see Table 2), resulting in a change in the final optimized flight speed.
4.4.2. The Influence of the RTA Interval Maximum Value on the Optimization Results. In formula (33), selecting $t_{2, \min }=760 \mathrm{~s}$, setting $t_{2, \max }$ variation range is $\left[\begin{array}{ll}770 & 820\end{array}\right] \mathrm{s}$ and step size is $10 \mathrm{~s}$. Each circulation optimization result is recorded when $t_{2, \text { min }}$ change, as shown in Figure 12 . With the $t_{2, \max }$ increase, the optimum fitness also presents a 


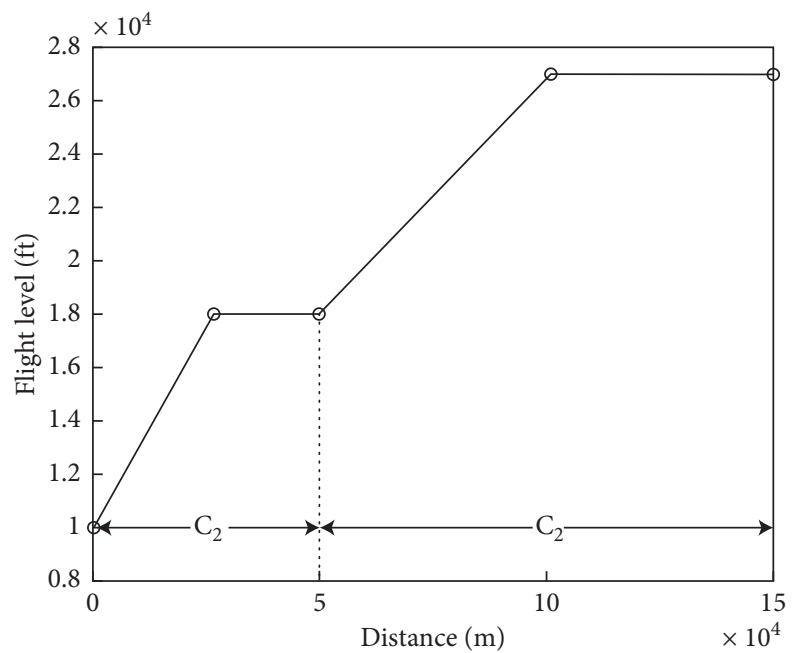

Figure 10: Optimal trajectory when $w_{1}=0.5, w_{2}=0.4$, and $w_{3}=0.1$.
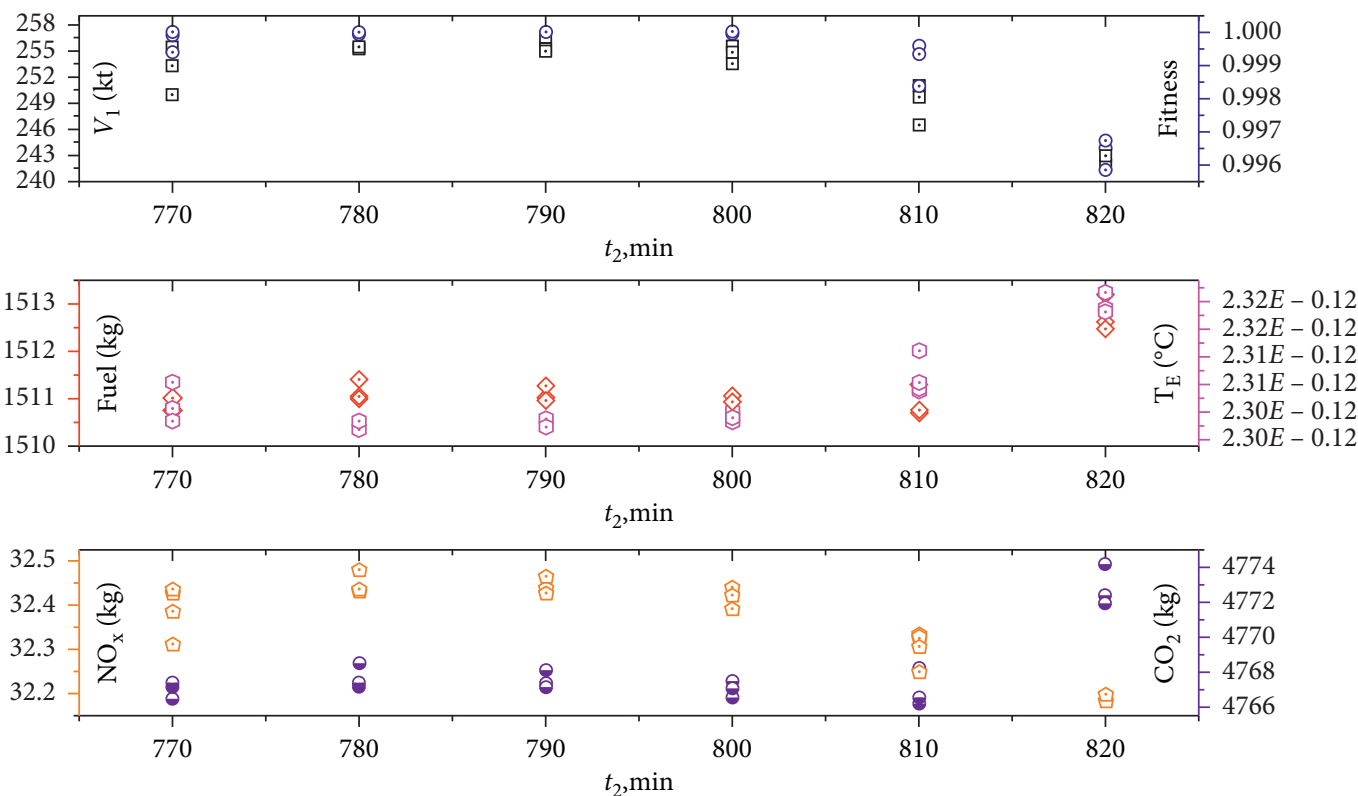

Figure 11: The influence trend of $t_{2 \text {, min }}$ on optimization results.

gradual increase trend and has a growth trend in the second half.

The variation trend of aircraft fuel consumption and flight speed is basically the same, and both are showing a downward trend. Moreover, the downward trend is obvious when $\left[t_{2, \min }, t_{2, \max }\right]=[760,820] \mathrm{s}$ and then turns. The main reason is that the aircraft's flight speed approaches the optimal value as the time interval moves back. The total temperature rise showed a trend of first decrease and then increase. The main reason is the $t_{2 \text {, max }}$ increase will increase the minimum flight speed which meets the RTA interval, thus affecting the change of aircraft fuel consumption and the consequent total temperature rise. This is the reason why the different trends in fuel consumption and total temperature rise as the flight speed changes. The $t_{2, \max }$ is increased to $820 \mathrm{~s}$ from $770 \mathrm{~s}$, and the corresponding fuel consumption is reduced by about $1.1 \%, \mathrm{CO}_{2}$ emission is reduced by $2.6 \%$, and $\mathrm{NO}_{\mathrm{x}}$ is reduced by $1.1 \%$, resulting in the total temperature rise increase less than $1 \%$.

\section{Conclusion}

In this paper, we explore the aircraft departure trajectory optimization under the multiple waypoint constraint condition while minimum fuel consumption and the minimum total temperature rise are caused by $\mathrm{CO}_{2}$ and $\mathrm{NO}_{\mathrm{x}}$ emissions. First, we establish the aircraft climbing trajectory model and analyze the aircraft flight parameters changing rules at different indicated airspeed. Then, we establish a multiobjective optimization model for the optimization target and 

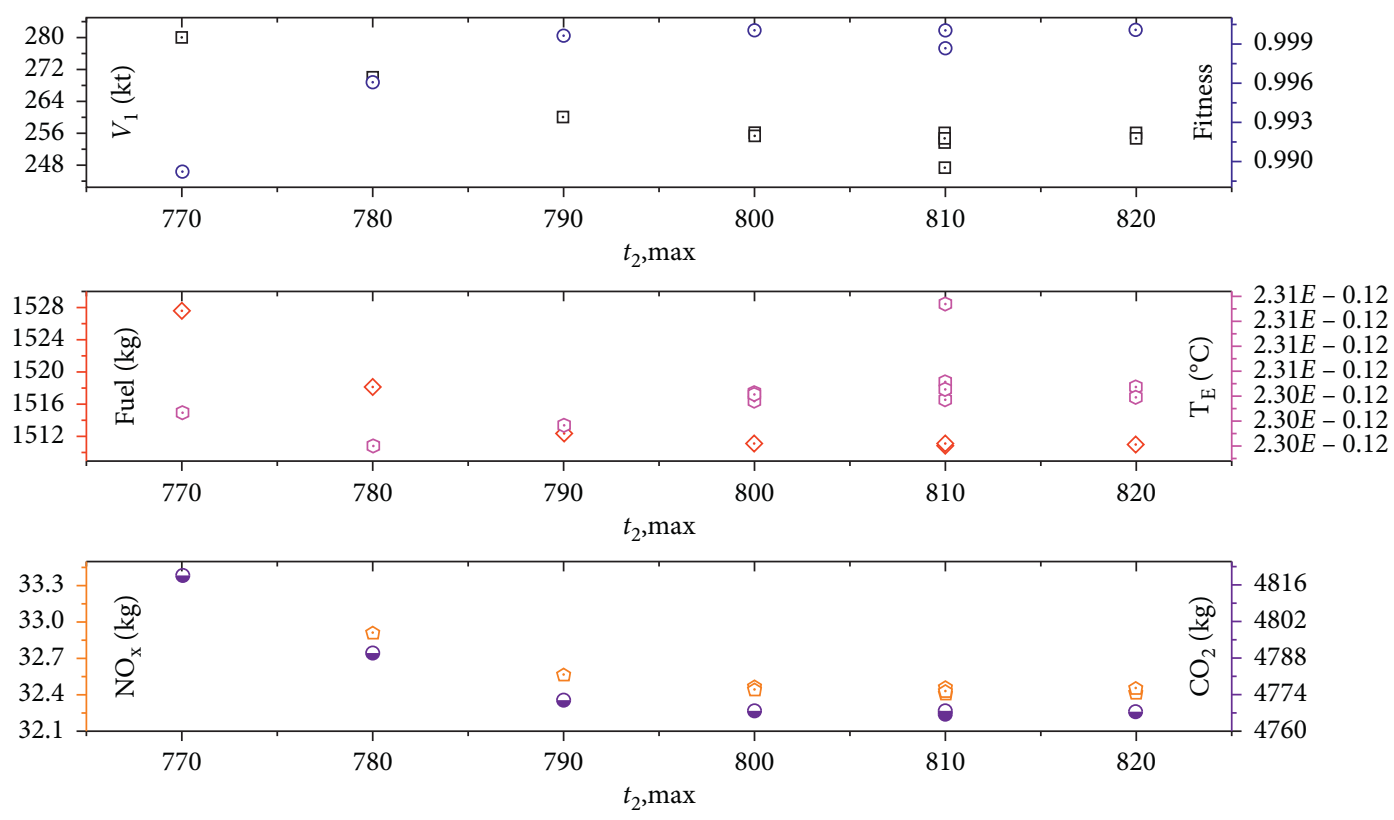

FIGURE 12: The influence trend of $t_{2, \max }$ on optimization results.

design a genetic algorithm to solve the problem. Finally, carrying out simulation based on the optimized parameters. According to these results, the conclusions are shown as follows:

(1) During aircraft climbing process, the total temperature rise variation trend is different due to fuel consumption and engine exhaust with speed change. The total $F$ optimal conditions relative to the total $T_{\mathrm{E}}$ optimal conditions of fuel consumption decreased by $0.71 \%$, and total temperature rise increased by $0.69 \%$. Therefore, the fuel consumption and exhaust gas can be realized by optimizing the total temperature rise tradeoff.

(2) In the climbing process, the higher the speed is, the gentler the climbing process is, and the optimal climbing speed at low height is greater than that at high height.

(3) The three optimization objectives' weights are set as $w_{3}=0.1, w_{1}=0.5$, and $w_{2}=0.4$, which can not only ensure flight convenience but also realize and optimize fuel consumption and total temperature rise compromise optimization.

(4) With the $w_{1}$ increase, the fuel consumption gradually decreases about $1.4 \%$, and the total temperature rise increases about $1.1 \%$. The increase of $\mathrm{CO}_{2}$ emissions decreases approximately $1.4 \%$, and the $\mathrm{NO}_{\mathrm{x}}$ emissions decreased by about $3 \%$.

(5) The increase of the RTA maximum time will lead to the fuel consumption reduction, while the total temperature rise increase caused by exhaust gas presents a decrease firstly and then an increasing trend. The RTA minimum interval value has slight influence on the optimized flight parameters. The $t_{2, \max }$ increases to 820 s from 770 s, the corresponding fuel consumption is reduced by about $1.1 \%, \mathrm{CO}_{2}$ emission is reduced by
$2.6 \%$, and $\mathrm{NO}_{\mathrm{x}}$ is reduced by $1.1 \%$, resulting in the total temperature rise increase less than $1 \%$.

This article provides a theoretical basis for the realization of safe, green, and coordinated operation of aircraft. In the future, we will conduct optimization studies on all flight stages of aircraft.

\section{Data Availability}

The data used to support the findings of this study are available from the corresponding author upon request. Most of the data of this study are included within the article.

\section{Conflicts of Interest}

The authors declare that they have no conflicts of interest.

\section{Acknowledgments}

This work was supported by the National Key R\&D Program of China (no. 2018YFE0208700) and the National Nature Science Foundation of China (no. 71971114).

\section{References}

[1] X. Wu and H. Yang, "Analysis of properties and delay propagation of air traffic based on complex network," Acta Aeronautica et Astronautica Sinica, vol. 38, no. S1, pp. 113119, 2017.

[2] J. Zhang, D. Sui, and X. Tang, "Aircraft trajectory prediction based on SDTHE algorithm," System Engineering Theory and Practice, vol. 34, no. 11, pp. 2955-2964, 2014.

[3] V. Ho-Huu, S. Hartjes, H. G. Visser, and R. Curran, "An optimization framework for route design and allocation of aircraft to multiple departure routes," Transportation Research Part D: Transport and Environment, vol. 76, pp. 273288, 2019. 
[4] V. Ho-Huu, S. Hartjes, H. G. Visser, and R. Curran, "Integrated design and allocation of optimal aircraft departure routes," Transportation Research Part D: Transport and Environment, vol. 63, pp. 689-705, 2018.

[5] H. G. Visser and R. A. A. Wijnen, "Optimization of noise abatement departure trajectories," Journal of Aircraft, vol. 38, no. 4 , pp. $620-627,2001$.

[6] H. G. Visser and S. Hartjes, "Economic and environmental optimization of flight trajectories connecting a city-pair," Proceedings of the Institution of Mechanical Engineers, Part G: Journal of Aerospace Engineering, vol. 228, no. 6, pp. 980-993, 2014.

[7] X. Prats, V. Puig, J. Quevedo, and F. Nejjari, "Multi-objective optimization for aircraft departure trajectories minimizing noise annoyance," Transportation Research Part C: Emerging Technologies, vol. 18, no. 6, pp. 975-989, 2010.

[8] R. Torres, J. Chaptal, C. Bès, and J.-B. Hiriart-Urruty, “Optimal, environmentally friendly departure procedures for civil aircraft," Journal of Aircraft, vol. 48, no. 1, pp. 11-22, 2011.

[9] Y. Tian, X. He, Y. Xu, L. Wan, and B. Ye, "4D trajectory optimization of commercial flight for green civil aviation," IEEE Access, vol. 8, pp. 62815-62829, 2020.

[10] Y. Xu and X. Prats, "Effects of linear holding for reducing additional flight delays without extra fuel consumption," Transportation Research Part D: Transport and Environment, vol. 53, pp. 388-397, 2017.

[11] P. Adrian, D. Ramon, L. Piotr et al., "Arrival traffic synchronisation with rtas and fuel.efficient trajectorie," in Proceedings of the AIAA Aviation Technology, Integration, and Operations Conference, Denver, CO, USA, June 2017.

[12] Y. Higuchi, N. Kitazume, K. Tamura et al., "Optimal arrival time assignment and control analysis using air traffic data for tokyo international airport," in Proceedings of the AIAA Guidance, Navigation, and Control Conference, San Diego, CA, USA, January 2017.

[13] S. Vilardaga and X. Prats, "Operating cost sensitivity to required time of arrival commands to ensure separation in optimal aircraft 4D trajectories," Transportation Research Part C: Emerging Technologies, vol. 61, pp. 75-86, 2015.

[14] A. Murrieta-Mendoza, H. Antoine, and B. Ruxandra, "Mach number selection for cruise phase using ant colony algorithm for RTA constrains," in Proceedings of the International Conference on Air Transport INAIR 2015, Armsterdam, UK, November 2015.

[15] A. Murrieta-Mendoza, A. Bunel, and R. Mihalea Botez, "Aircraft vertical reference trajectory optimization with a RTA constraint using the ABC algorithm," in Proceedings of the 16th AIAA Aviation Technology, Integration, and Operations Conference, pp. 13-17, Washington, DC, USA, June, 2016.

[16] J. Wan, H. Zhang, F. Liu et al., "Optimization of aircraft climb trajectory considering environmental impact under RTA constraints," Journal of Advanced Transportation, vol. 2020, Article ID 2738517, 17 pages, 2020.

[17] R. Gu, J. Yuan, X. Han, Z. Wei, and N. Li, "Flight performance optimization considering environmental impact under multiRTA constraints," International Journal of Aeronautical and Space Sciences, vol. 20, no. 4, pp. 964-977, 2019.

[18] User Manual for the Base of Aircraft Data (BADA), Revision 3.7 [S] 2004, https://www.eurocontrol.int/publication/usermanual-base-aircraftdata-bada-revision-37.

[19] K. P. Shine, J. S. Fuglestvedt, K. Hailemariam, and N. Stuber, "Alternatives to the global warming potential for comparing climate impacts of emissions of greenhouse gases," Climatic Change, vol. 68, no. 3, pp. 281-302, 2005.
[20] R. Zhang, A Study on Radiative Forcing and Global Warming Potential of Long-Life Greenhouse Gases $\mathrm{CH}_{4}$ and $\mathrm{N}_{2} \mathrm{O}$, Nanjing University of Information Science \& Technology, Nanging, China, 2011.

[21] C. Azar and D. J. A. Johansson, "Valuing the non- $\mathrm{CO}_{2}$ climate impacts of aviation," Climatic Change, vol. 111, no. 3-4, pp. 559-579, 2012.

[22] European Aviation Safety Agency, ICAO Engine Exhaust Emissions Databank [EB/OL], http://easa.europa.eu/ document.library/icao.aircraft.engineemissions.databank. 